\title{
Adrian Jackson
}

\section{Augusto Boal - a Theatre in Life}

Augusto Boal died on 2 May 2009 at the age of seventy-eight. The following tribute is by Adrian Jackson, who knew Boal not only as translator into English of five of his books and collaborator on many of his workshops, but as a leading practitioner deploying Boal's techniques, notably as founder in 1991 and Artistic Director of Cardboard Citizens, the UK's only homeless people's professional theatre company, for whom he has directed more than twenty productions, including two in association with the Royal Shakespeare Company Pericles, played in a disused warehouse off the Old Kent Road, and Timon of Athens, which toured Stratford and the Belfast Festival. The company's most recent production was Mincemeat, a Second World War epic based on the story of the Man Who Never Was.

IN A RADIO PROGRAMME I did shortly after Augusto Boal's death, the interviewer threw me by asking which theatre directors Boal had particularly influenced; she wanted me to name known stars of the British theatrical firmament, and I struggled to answer her question, not because I do not believe that there are important figures in theatre to whom that influence would apply, but because it was the wrong question. Augusto Boal's influence stretches far beyond the narrow coteries of theatre, into every aspect of engaged social life, from artist to activist, social worker to trade unionist, teacher to therapist - I could go on, but I would leave out a category.

That is the true mark of his importance: the fact that his theory and practice extended into so many different areas of public life; in this sense, it is arguable that he is a bigger figure than Brecht and Stanislavsky, whose names are probably little known to the nontheatregoing public, or outside the rehearsal room or seminar room.

I will not attempt to trace the full and detailed arc of Augusto Boal's life, which has been effectively chronicled elsewhere; I have been his translator and collaborator, not his biographer. He himself wrote, albeit probably with the normal degree of selective reporting of the autobiographer, of his early life and theatrical beginnings in Hamlet and the Baker's Son. Suffice it to say that he moved with an artistically and politically driven restlessness comparatively rapidly from the confines of the established theatre out into the larger world of social and activist engagement.

The early days at the Arena Theatre had involved the deliberate Brazilianization of culture, which was part of a larger nationalist movement of cultural reappropriation at the time. But soon enough, affected again by the temper of the times, Boal's part of Arena broke away to experiment with more direct combinations of politics and art, out in the field. This is the phase of Boal's most protracted use of agit-prop (though he would continue to deploy theatre from time to time in the same way, throughout his life). In the way that Boal had of book-ending periods of his life, usually with an epiphany brought upon him by outside circumstances, this phase ends with the much-told story of the peasant Virgilio who leads Augusto to seek in future to adopt as mantra Che Guevara's 'Solidarity means running the same risks.'

Boal undoubtedly did run major risks, especially in this part of his life. He was imprisoned, tortured, and then exiled. Then began a long odyssey which did not take him back to Brazil for well over a decade. Even when he returned, this compulsive travelling-teaching had become so embedded that he continued in similar globetrotting mode virtually up till his death.

It is arguable that it was this exposure to so many different people and cultures that 


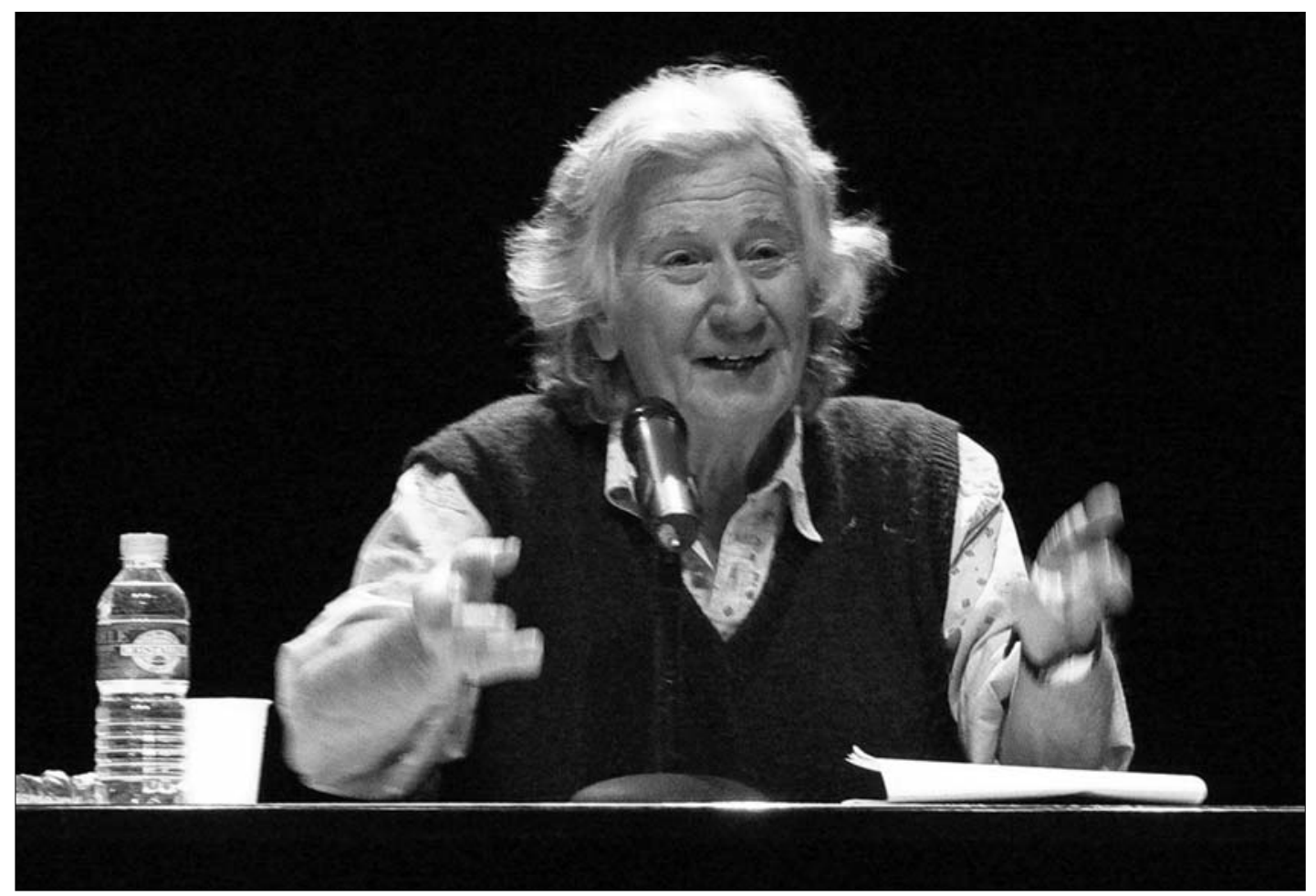

lent such richness to his practice and enabled it to become so all-embracing; from a theoretical base rooted in Brazil, in Freire and other Latin American thinkers and pedagogues, Boal collided with ideas and practices from all parts of the world. As I have written elsewhere, he collected games and exercises from wherever he went, bringing them into the Theatre of the Oppressed proudly labelled with their place of origin, and carefully organized into the systematic and ethically driven approach which is what distinguishes the arsenal of TO from a mere collection of diverting drama pastimes.

Latterly, he became more and more concerned to ensure that this practice should not be simply detached from the ethical base in which it was grounded. In the end he succeeded in building an edifice - or to use his preferred analogy, planting a tree - which should be strong enough to survive his passing, and to thrive and grow.

I translated five books by Augusto Boal, and have worked intensively with and taught his methodology for the best part of twenty years. I founded and still lead a company working with homeless people and refugees, Cardboard Citizens, which is based substantially on the Theatre of the Oppressed. I was not a translator by trade - rather a practitioner who had a good understanding of the work. The first two books I translated from French, as Boal's latest versions of those books had been copiously revised by him in French, and that was indeed where he was living and working when he wrote them. The next three required me to learn to read Portuguese, though my spoken Portuguese is non-existent. Augusto was always supportive and complimentary of my translations - on more than one occasion, he wrote the same comment on the flyleaf of a book, not remembering that he had done it before 'Now I understand better what it was I wanted to say.'

Typically he was a very polite companion, though his main focus was on work. Even outside the workshop or rehearsal space, his focus was always on his next projects or book. All the time he visited London, he hardly ever took a day out (as I often encouraged him to do) to indulge in anything approximating to tourism - though when he was persuaded to look around the Globe, 
with the added bonus of dinner with its then director, Mark Rylance, he relished the opportunity. He did like the regular theatre though we rarely had a successful outing to a show together - and he still had hankerings for directing professional productions, which he ceased to do outside Brazil more than ten years ago. It is a matter of sadness that Cicely Berry, his friend and ally at the RSC, never managed to persuade that institution to give him a full production - the Hamlet that he dreamed of doing.

Over about twenty years I got to see Augusto about once or twice a year, usually for a week when he would be delivering teaching for Cardboard Citizens, or occasionally when we were working together in this country or abroad; when working on his books, we would be corresponding for a period quite intensively while I tried to get the right meanings out of his texts. I called him friend, mentor, sometimes surrogate father, and he generously called me brother. But there was a twenty-five-year gap between our ages and an ocean between our experiences, which meant that there would always be differences of understanding.

And in any case he was a private man. Like many people in the public eye, he was careful what he showed to the world, and conscious all the time that his every gesture, reaction, and thought would be the object of study and interest. And yet he bore the burden of fame and respect lightly.

When working on the translations, the exchange of letters and calls, superseded by emails for the later books, could sometimes be a frustrating process. A question would usually lead not to a straightforward answer, but to the addition of a further chunk of text, which would not always throw light on the original enquiry. He was, even in the production of his books, determinedly his own man - a footnote could be as long as a page of text, and he would resist attempts to do the conformist thing and simply integrate it into the text.

Very early in our relationship, Boal came to eat at the North West London flat I lived in at the time. He was never a hugely social animal, more comfortable with a small group of friends and supporters than in any grander setting; this extended to his eating habits - he was simply uninterested in food, happy to eat wherever, and clearly distinctly uncomfortable in a posh restaurant. That night we chatted happily enough, though carefully, about his books and so on, till catastrophically and without warning, the ceiling of my living room fell down (I would later joke in speeches that Augusto's story-telling was always guaranteed to bring the house down). But with this minor disaster Augusto came into his own - in a kind of way he was more relaxed than he had been at any time earlier in the evening. As we carted bits of mortar through to the bin, he threw himself into the salvage operation and generally tried to dust everything down. He had something to do, and was never happier than when doing, preferably something useful.

He had his contradictions, as do we all. Having created the remarkable worldwide operation of the Theatre of the Oppressed, having given away his secrets to all and sundry, he sometimes seemed torn between the desire to seek to regulate this potential empire, both in terms of quality and content, and the knowledge that the cat was out of the bag. The ethos demanded - the whole point of the ethos is and was - universal access to the tools, provided that their deployment was for the good of humanity. But how to ensure this? And how to avoid terrible misappropriations and misunderstandings?

We witnessed a few of these in the early Theatre of the Oppressed conferences, and one could feel Boal's frustration, though it was rarely voiced. As a man who had come from the theatre, he often rightly felt that it would not take much to improve the theatricality of some of the work on offer - but many of the makers of the work were of course not from the theatre at all, that was the whole point, and how and why should they know how to improve that side of things? This I suppose partly led to the later attempt to codify a working aesthetic for TO in The Aesthetics of the Oppressed, the book he was revising at the time of his death.

I have described elsewhere the awful moment in Paris in the mid-nineties, when it 
became clear that an Estonian offering at the TO festival was nothing more nor less than out-and-out racism. It took a disconcertingly long time before the politeness of festival attendees gave way to discerning anger and it took an even longer time before Augusto used his considerable gravitas, to damn this unpleasant and unthinking piece with faint insult, saying that it might be good as a game for Club Mediterranée, but it had nothing to do with Forum Theatre.

The other misappropriation which he positively hated was the colonization of Forum Theatre by business. For him this was like handing tools to the enemy - and this sense of the world of business being the enemy, however theoretically, corporately, socially responsible, persisted, ingrained in the early years, and refusing to be shifted or deceived by short-term apparent changes in attitude. In the end, Boal remained remarkably consistent in his political outlook, holding to essentially the same theories even as the world appeared to change around him. Of course he was right, as we all know now: in the ma- jority of cases, nothing had really changed except the words and the willingness to be open about acquisitiveness and greed.

How will we remember him? Daily for me, as every day I work with the tools he gave me. We should remember him as a quester, a searcher and researcher, constantly inventing new approaches and variations to old, all with the goal of bringing to fruition his dream of a world-changing theatrical practice. And that dream is there, he achieved it witness the outpourings of gratitude and grief on the Theatre of the Oppressed website (theatreoftheoppressed.org), from far-flung corners of the globe, by a rainbow coalition of practitioners all of whom have adopted and adapted Boal to their own ends.

I am sure he had much more to do, but he had already done much. Julian Boal told me his end was like the felling of a great tree (one thinks of his much-loved Tree of the Theatre of the Oppressed), rather than a gradual decline, and that is what it looked like. Better that way, for a man of action, a man of acting. 